\title{
Accumulation of Odd-Numbered Long-Chain Fatty Acids in Fetuses and Neonates with Inherited Disorders of Propionate Metabolism
}

\author{
UDO WENDEL, REgula BAUMGaRTNER, SYB B. VAN DER MEER, AND LEO J. M. SPAAPEN \\ University Children's Hospital Düsseldorf, D-4000 Düsseldorf, Germany [U.W.]; University Children's Hospital \\ Basel, CH-4005 Basel, Switzerland [R.B.]; Academic Hospital Maastricht, Department of Pediatrics, NL-6201 \\ BX Maastricht, The Netherlands (S.B.v.d.M.); and University of Limburg, Department of Genetics and Cell \\ Biology, NL-6200 MD Maastricht, The Netherlands [L.J.M.S.)
}

\begin{abstract}
Fetuses affected with propionic acidemia incorporate great amounts of odd-numbered long-chain fatty acids (OLCFA) into their body lipids. This is due to abundant supply with precursor amino acids of propionylCoA throughout pregnancy. After birth, the lower provision of precursor amino acids during dietary treatment compared with fetal life results in a decline of propionyl-CoA production and therefore OLCFA synthesis. However, the observed decrease of OLCFA may also partly reflect the recovery from acute ketoacidotic episodes that the patients experienced soon after birth as long as they were undiagnosed. In a patient with vitamin $B_{12}$-responsive methylmalonic aciduria treated prenatally with large doses of vitamin $B_{12}$ given to the mother, the cord plasma lipids contained normal amounts of OLCFA. This indicates that prenatal therapy led to an increased flux of propionyl-CoA through the defective methylmalonyl-CoA mutase step. Thus, in addition to the quantification of a decline in methylmalonic acid in maternal urine, OLCFA in cord blood lipids might be a further parameter for evaluating prenatal treatment in patients with vitamin $B_{12}$-responsive methylmalonic aciduria. (Pediatr Res 29: 403-405, 1991)
\end{abstract}

\section{Abbreviations}

PA, propionic acidemia

MMA, methylmalonic aciduria

OLCFA, odd-numbered long-chain fatty acid

The relative abundance of OLCFA in body lipids of patients with defective propionate metabolism (PA, MMA) can be used for monitoring these patients, inasmuch as it is influenced by the clinical management (1). Increased accumulation of OLCFA has already been found in newborns who had died with one of these disorders shortly after birth (2-5). Here we show that in affected fetuses increased OLCFA production from the precursor amino acids of propionyl-CoA is a process that starts early in fetal life. It appears that excess accumulation of OLCFA in a fetus with vitamin $\mathrm{B}_{12}$-responsive MMA could be reduced by prenatal therapy.

\section{PATIENTS AND METHODS}

Patients. Fetuses Ho 1 and Ho 2 were at risk for PA and amniocenteses were performed in the 16th gestational wk. In

Received January 30, 1990; accepted November 6, 1990.

Correspondence: Udo Wendel, Kinderklinik der Heinrich-Heine-Universität, Düsseldorf, Moorenstr. 5, D-4000 Düsseldorf, Germany.

Supported by Grant We 614/5-3 (U.W.), Deutsche Forschungsgemeinschaft. both fetuses, PA was diagnosed prenatally by means of the determination of methylcitrate in amniotic fluids and by enzymatic studies in cultured amniocytes. Activity of propionyl-CoA carboxylase measured as enzyme-dependent incorporation of ${ }^{14} \mathrm{C}$-bicarbonate into acid-nonvolatile products (6) in cultured amniocytes was 14 and $5.3 \mathrm{pmol} / \mathrm{mg}$ protein $\times$ min, respectively (controls: mean $\pm \mathrm{SD}, 1297 \pm 668$; range, 472-2629; $n=14$ ). In each fetus, abortion was induced at wk 21 of gestation. After abortion, erythrocytes, plasma, and whole blood, as well as liver, brain, and s.c. tissue, were obtained and immediately frozen at $-20^{\circ} \mathrm{C}$.

M.B., the second child of a healthy and unrelated couple, was born at term. The first child had suffered from ventricular septal defect and had died at 3 wk of age of unknown cause. M.B. presented with vomiting, hypotonia, respiratory insufficiency, and coma at $5 \mathrm{~d}$ of age. He was severely hyperammonemic (1.8 $\mathrm{mmol} / \mathrm{L}$ ). The gas chromatography-mass spectrometry of urine suggested a diagnosis of PA, which was confirmed later by enzymatic analysis in cultured fibroblasts. Activity of propionylCoA carboxylase in fibroblasts was $7.0 \mathrm{pmol} / \mathrm{mL}$ protein $\times$ min (controls: mean $\pm \mathrm{SD}, 1087 \pm 356$; range, 564-2005; $n=21$ ). At $\mathrm{d} 9$, continous arteriovenous hemofiltration and dietary management was begun in the University Children's Hospital, Innsbruck. At d 11,13,23, and 44, the fatty acid composition in lipids of red cell membranes and plasma was studied. Despite a successful treatment of initial coma, the patient died at the age of 3 mo during a metabolic crisis.

M.Y., a boy, is the second child of healthy consanguineous Turkish parents. Pregnancy and delivery were normal. A 3-y-old daughter is healthy; two children had died of unknown causes in Turkey at $2 \mathrm{wk}$ of age. The patient presented at $9 \mathrm{~d}$ of age with hyperammonemia $(650 \mu \mathrm{mol} / \mathrm{L})$ and a slight metabolic acidosis and was treated with peritoneal dialysis. Gas chromatography of the urine showed a high excretion of methylmalonic acid (7.2 $\mathrm{mol} / \mathrm{mol}$ creatinine). After peritoneal dialysis lasting for $3 \mathrm{~d}$, he was started on a low-protein regimen supplemented with nontoxic amino acids, $\mathrm{L}$-carnitine, and vitamin $\mathrm{B}_{12}$. It appeared that he suffered from vitamin $B_{12}$-responsive MMA. Later, the diagnosis was confirmed in the patient's fibroblasts. Incorporation of ${ }^{14} \mathrm{C}$-propionate without hydroxycobalamin added was about $10 \%$ that of controls and showed a 3.5-fold increase with supplemented hydroxycobalamin $(100 \mu \mathrm{g} / \mathrm{L}$ of culture medium). At the age of $20 \mathrm{mo}$, the boy was doing well. At d 9 and 24 , the fatty acid composition in red cell and plasma lipids was studied.

In a pregnancy at risk for vitamin $B_{12}$-responsive MMA, prenatal diagnosis performed gas chromatography-mass spectrometry analysis of amniotic fluid obtained at 16 gestational wk and by measuring $\left[{ }^{14} \mathrm{C}\right]$ propionate incorporation into cultured amniocytes ( $15 \%$ of control values; Dr. W. J. Kleijer, Rotterdam) demonstrated that the fetus was affected. For prenatal therapy, 
the mother was given high oral doses of vitamin $B_{12}(22.5 \mathrm{mg} / \mathrm{d}$ in three doses) starting in the 27th wk of gestation. On this treatment, the maternal urinary methylmalonate excretion was around $10.3 \mathrm{mmol} / \mathrm{mol}$ creatinine, which leveled off during the last $5 \mathrm{wk}$ of gestation (7). A clinically healthy female infant was born by spontaneous delivery at 41 wk of gestation. After birth, an increase in methylmalonate excretion was observed, reaching $2.1 \mathrm{~mol} / \mathrm{mol}$ creatinine on the $3 \mathrm{rd} \mathrm{d}$ of life. Administration of hydroxycobalamin by intramuscular injection $(1 \mathrm{mg} / 2 \mathrm{~d})$ was started on $\mathrm{d} 4$. By this measure, methylmalonate excretion was successfully reduced. The OLCFA content was measured in the plasma lipids of cord blood.

The diagnosis of vitamin $B_{12}$-responsive MMA was confirmed in the patient's fibroblasts by Dr. B. Fowler, Manchester, UK. Incorporation of ${ }^{14} \mathrm{C}$-propionate without hydroxycobalamin added was about $15 \%$ that of controls and reached the control range with supplemented hydroxycobalamin $(1000 \mu \mathrm{g} / \mathrm{L}$ of culture medium).

Methods. Red blood cells were isolated from EDTA-blood and washed as described (8). Plasma and erythrocytes were stored at $-20^{\circ} \mathrm{C}$ until analysis. The cord blood of controls was collected into EDTA-tubes, and erythrocytes and plasma were separated within $24 \mathrm{~h}$. Fetal tissues and tissues from deceased prematures were stored at $-20^{\circ} \mathrm{C}$ until analysis.

The work-up of the red cell lipids was exactly as described previously (8).

Lipids were extracted from $1.0 \mathrm{~mL}$ plasma with chloroform/ methanol (9). The different lipid classes were separated on silica gel plates (Merck, Darmstadt, Germany) with a run of petroleum/ether/acetic acid $(75 / 25 / 1, \mathrm{vol} / \mathrm{vol} / \mathrm{vol})$ and a run of chloroform $/ \mathrm{methanol} /$ water $(65 / 25 / 4, \mathrm{vol} / \mathrm{vol} / \mathrm{vol})$. The bands containing sterol esters, triglycerides, and phospholipids were identified by comparison with appropriate standards and removed by scraping. The fatty acids were transesterified with methanol and hydrochloric acid (10).

The tissues (1-20 mg wet wt) were homogenized by use of a microdismembrator (Braun Melsungen, Germany) under liquid nitrogen (maximal power, $0.5 \mathrm{~min}$ ). The tissue homogenates were extracted with $7.5 \mathrm{~mL}$ methanol/chloroform $(2 / 1$, vol/vol). After standing overnight in the dark at room temperature, 2.5 $\mathrm{mL}$ chloroform and $2.5 \mathrm{~mL}$ water were added. After shaking, the mixture was allowed to stand for $15 \mathrm{~min}$ on ice. Then it was centrifuged at $1500 \times g(20 \mathrm{~min}$, room temperature $)$ and the supernatant was discarded. The lipid extracts (lower layers) were evaporated to dryness at $35^{\circ} \mathrm{C}$. The residue was transesterified by base catalysis with sodium methoxide as described previously (8).

Analysis of the fatty acid methyl esters by capillary column gas liquid chromatography was exactly as we have described (8). Fatty acids of 14-22 carbon length were identified by comparison with authentic standards.

In each sample, the proportions of the individual OLCFA15- and 17-carbon saturated and 17-carbon monounsaturated fatty acids (C 15:0, C 17:0, C 17:1)-as well as their sums were calculated and expressed as a percentage of the total $\mathrm{C} 14-\mathrm{C} 22$ fatty acids in the sample.

\section{RESULTS}

Different tissues of two fetuses of 21 wk gestation affected with PA contained much more OLCFA than tissues from premature or full-term controls (Table 1). Among the specimens, the OLCFA content was highest in plasma sterol esters, liver, and s.c. tissue and lowest in brain.

The OLCFA levels in red cell and plasma lipids of two newborns with PA and MMA are shown in Table 2. Plasma lipids in the PA patient contained higher amounts of OLCFA than those in the MMA patient. Both patients experienced a severe metabolic episode before they were diagnosed. In each lipid fraction studied, the high OLCFA level present shortly after birth
Table 1. OLCFA content in tissues from two fetuses (21 wk of gestation) affected with $P A$ and from premature and term controls (\% total C14-C22 fatty acids)

\begin{tabular}{lccc}
\hline & $\begin{array}{c}\text { Fetus } \\
\text { Tissue }\end{array}$ & $\begin{array}{c}\text { Fotus } \\
\text { HO }\end{array}$ & $\begin{array}{c}\text { Controls } \\
\text { (mean } \pm \text { SD; range) }\end{array}$ \\
\hline Red cell lipids & 1 & 2 & $1.0 \pm 0.2(0.66-1.20)^{*}$ \\
Whole venous & 3.5 & & $0.9 ; 1.2 \dagger$ \\
$\quad$ blood & & 6.6 & \\
Plasma lipids & & & \\
$\quad$ Phospholipids & 4.8 & & $1.0 \pm 0.1(0.73-1.14)^{*}$ \\
Triglycerides & 5.6 & & $1.9 \pm 0.6(0.90-2.94)^{*}$ \\
Sterol esters & 8.3 & & $2.1 \pm 0.8(1.23-3.32)^{*}$ \\
Liver & 5.8 & 6.2 & $1.0 ; 1.1 \ddagger$ \\
Brain & 2.9 & 3.5 & \\
Subcutaneous tissue & 5.2 & 5.8 & $1.6 ; 1.8 \ddagger$ \\
\hline
\end{tabular}

* Cord blood at term, $n=7$.

$\dagger$ Cord blood at term, $n=2$.

$\ddagger$ Deceased prematures, 26 gestational wk, $n=2$.

Table 2. Alterations with age of \% of OLCFA in red cell and plasma lipids in two newborns with $P A$ and $M M A$

\begin{tabular}{lrcccc}
\hline & & \multicolumn{4}{c}{ OLCFA (\% of total fatty acids) } \\
\cline { 3 - 6 } Disorder & Age & (d) & Red cell & \multicolumn{4}{c}{ Plasma } \\
\cline { 4 - 6 } \cline { 4 - 6 } PA & 11 & 2.7 & 8.2 & 11.8 & 8.0 \\
& 13 & 2.8 & 5.3 & 8.8 & 8.5 \\
& 23 & 2.2 & 3.8 & 4.6 & 3.7 \\
& 44 & 1.7 & 2.5 & 2.5 & 1.5 \\
MMA & 9 & 3.1 & 3.5 & 4.8 & 5.6 \\
& 24 & 1.8 & 2.4 & 2.8 & 1.7 \\
\hline
\end{tabular}

Table 3. OLCFA content in cord plasma lipids of prenatally treated newborn with vitamin $B_{12}$-responsive $M M A$ and normal controls (\% total fatty acids)

\begin{tabular}{lcc}
\hline Lipid fraction & $\begin{array}{c}\text { MMA } \\
\text { patient }\end{array}$ & $\begin{array}{c}\text { Controls* } \\
\text { (range) }\end{array}$ \\
\hline Phospholipids & 1.1 & $0.73-1.14$ \\
Triglycerides & 2.2 & $0.90-2.94$ \\
Sterol esters & 1.5 & $1.23-3.32$ \\
\hline
\end{tabular}

* Controls: cord blood at term, $n=7$.

declined substantially during the first 4-6 wk of life while patients were on treatment.

We found normal OLCFA contents in cord blood lipids of a child with vitamin $\mathrm{B}_{12}$-responsive MMA who was treated prenatally with large doses of vitamin $B_{12}$ given to the mother (Table 3). By extrapolation from our data in fetuses with PA and newborns with PA and MMA, as well as from the increased urinary methylmalonate excretion of the mother before institution of $\mathrm{B}_{12}$-therapy, this might indicate that at least during the last weeks of fetal life the production of excess OLCFA was reduced.

\section{DISCUSSION}

We showed that fetuses affected with a disorder of propionate degradation incorporate great amounts of OLCFA into body lipids. At approximately 20 wk of gestation, the OLCFA content in various lipids of fetuses with PA was very high and was similar to that found shortly after birth. Due to a transplacental gradient of free amino acids in favor of the fetus providing the fetus with optimal amino acid nutrition (for ref. see 11), relatively high concentrations of the free precursor amino acids-valine, isoleucine, methionine, and threonine-exist in fetal blood. This results in the formation of large amounts of propionyl-CoA in the 
tissues, which under the highly anabolic conditions of fetal life augments OLCFA production and incorporation into newly synthesized lipids. The fact that part of propionyl-CoA is eliminated from the fetus as propionate derivatives offers the possibility of prenatal diagnosis of PA and MMA by means of the determination of methylcitric acid in amniotic fluid (12). Another class of propionyl-CoA-derived compounds found in amniotic fluids of fetuses with PA and MMA are methyl-branched dicarboxylic acids (13).

Elevated OLCFA were also found in erythrocyte and plasma lipids of newborns with PA and MMA. By extrapolation from our data, a higher accumulation of OLCFA could be expected for fetuses with PA than MMA. This is in line with the finding that the concentration of methylcitric acid in amniotic fluids of fetuses with PA is somewhat higher than in those with MMA (14) suggesting that the former have higher elevations of propionyl-CoA.

After birth, two facts may account for the observed decline of OLCFA in plasma and red cell lipids: 1 ) the physiologic shift in the fatty acid pattern of plasma lipids during the first $4 \mathrm{wk}$ of age (15), which results in a reduction of the percentage of monounsaturated fatty acids-here heptadecenoic (C 17:1) acid and 2) the lower provision of precursor amino acids during dietary treatment compared with fetal life leading to a decline in propionyl-CoA production. However, in the present cases the decrease could at least partly reflect recovery from the acute ketoacidotic episodes (see Fig. 2 of ref. 1) that both neonates experienced before first blood samples were taken.

It is likely that substantial amounts of propionyl-CoA and methylmalonyl-CoA during prenatal life cause injury to the fetus. In that respect, the highly active flux of propionyl-CoA into the OLCFA synthesis might have a beneficial and detoxicating effect by reducing the fetal propionyl-CoA pool. However, it cannot be answered whether great amounts of OLCFA in brain lipids, per se, are responsible for impaired neurologic development in those patients, as has been proposed (5).

The OLCFA might be regarded as a storage form of propionyl$\mathrm{CoA}$ accumulating already in fetal life. During periods of strong tissue catabolism, such as in early days of life, the stimulated breakdown of adipose tissue might importantly contribute to the accumulation of extensive amounts of toxic propionyl-CoA in the mitochondria, and thus contribute to the severe illness of these patients.

Prenatal treatment of a fetus affected with vitamin $B_{12}$-responsive MMA during the last $13 \mathrm{wk}$ of gestation with large doses of vitamin $B_{12}$ given to the mother reduced the increased maternal excretion of methylmalonic acid and led to a normal OLCFA content in plasma lipids at birth. The pharmacologic vitamin dose was given to diminish the accumulation of various metabolites including propionyl-CoA by an increased flux through the defective methylmalonyl-CoA mutase step. Until now, the success of prenatal treatment could be followed only indirectly by monitoring methylmalonic acid in maternal urine (16). Although it was suggested that the more important effect of vitamin $B_{12^{-}}$ treatment was on fetal metabolism, it could not satisfactorily be clarified whether the decrease in maternal methylmalonic acid excretion could have resulted from an effect on fetal metabolism alone or on fetal and maternal metabolism combined (16). The normal OLCFA content of cord plasma lipids in our patient appears to demonstrate more directly that in fact the metabolic block in the fetus was improved by vitamin $B_{12}$-treatment. Thus, OLCFA in cord blood lipids after birth might be an additional parameter for the evaluation of effectiveness of prenatal treatment of fetuses with vitamin $B_{12}$-responsive MMA and perhaps also with holocarboxylase synthetase deficiency (17).

Acknowledgment. The authors acknowledge the skillful laboratory work of Elke Diekmann

\section{REFERENCES}

1. Wendel U 1989 Abnormality of odd-numbered long-chain fatty acids in erythrocyte membrane lipids from patients with disorders of propionate metabolism. Pediatr Res 25:147-150

2. Hommes FA, Kuipers JRG, Elema JD, Jansen JF, Jonxis JHP 1968 Propionic acidemia, a new inborn error of metabolism. Pediatr Res 2:519-524

3. Gompertz D, Storrs CN, Bau DCK, Peters TJ, Hughes EA 1970 Localisation of enzymic defect in propionic acidaemia. Lancet 1:1140-1143

4. Gompertz D 1971 The distribution of 17 carbon fatty acids in the liver of a child with propionic acidaemia. Lipids 6:576-580

5. Kishimoto Y, Williams M, Moser HW, Hignite C, Biemamm K 1973 Branched-chain and odd-numbered fatty acids and aldehydes in the nervous system of a patient with deranged vitamin $\mathrm{B}_{12}$ metabolism. $\mathbf{J}$ Lipid Res 14:69-77

6. Suormala T, Wick H, Bonjour JP, Baumgartner ER 1985 Rapid differential diagnosis of carboxylase deficiencies and evaluation for biotin-responsiveness in a single blood sample. Clin Chim Acta 145:151-162

7. Spaapen LJM, van der Meer SB, Bakker JA 1989 Prenatal treatment of a fetus with vitamin $B_{12}$-responsive methylmalonic acidemia. Abstracts of the 27th Annual Society for the Study of the Inborn Errors of Metabolism Symposium

8. Laryea MD Cieslicki P Diekmann E, Wendel U 1988 Analysis of the fatty acid composition of erythrocyte phospholipids by a based catalysed transesterification method-prevention of formation of dimethylacetals. Clin Chim Acta 171:11-18

9. Folch J, Lees M, Sloane Stanley GH 1957 A simple method for the isolation and purification of total lipids from animal tissues. J Biol Chem 226:497509

10. Stoffel W, Chu F, Ahrens EH 1969 Analysis of long-chain fatty acids by gasliquid chromatography. Anal Chem 31:307-308

11. Scriver CR, Rosenberg LE 1973 Amino acid metabolism and its disorders Saunders, Philadelphia, pp 51-53

12. Sweetman L 1984 Prenatal diagnosis of the organic acidurias. J Inherited Metab Dis 7(suppl 1):18-22

13. Jakobs C, Dorland L, Sweetman L, Duran M, Nyhan WL, Wadman SK 1984 Identification of methyl-branched chain dicarboxylic acids in amniotic fluid and urine in propionic and methylmalonic acidemia. Pediatr Res 18:11851191

14. Holm J, Ponders L, Sweetman L 1989 Prenatal diagnosis of propionic and methylmalonic acidaemia by stable isotope dilution analysis of amniotic fluid. J Inherited Metab Dis 12:271-273

15. Ciccoli L, Hayek Y, Berti D, Bracci R 1981 Fatty acid pattern of the erythrocyte lipids and plasma vitamin $\mathrm{E}$ in the first days of life. Biol Neonate 40:187195

16. Ampola MG, Mahoney MJ, Nakamura E, Tanaka K 1975 Prenatal therapy of a patient with vitamin $B_{12}$-responsive methylmalonic acidemia. $N$ Engl $J$ Med 293:313-317

17. Roth KS, Yang W, Allan L, Saunders M, Gravel RA, Dakshinamurti K 1982 Prenatal administration of biotin in biotin responsive multiple carboxylase deficiency. Pediatr Res 16:126-129 